\title{
Children and young people's participation in developing interventions in health and well-being: a scoping review
}

Ingrid Larsson * (D), Carin Staland-Nyman, Petra Svedberg, Jens M. Nygren and Ing-Marie Carlsson

\begin{abstract}
Background: Greater interest is being shown in participatory approaches, especially in research on interventions that concern children and young people's health and well-being. Although participatory approaches have user involvement in common, they differ in terms of the explicit guidance on how to actually involve and engage children and young people in health research. The aim of this scoping review was to systematically map recent research involving children and young people in the development of interventions targeting issues of health and well-being.
\end{abstract}

Methods: An interpretative scoping literature review based on: a scientific literature search in (health and social science) databases, reference lists, a manual search in key journals and contact with existing networks was conducted. A total of 4458 references were identified through the literature search, of which 41 studies published between 2000 and 2017 were included in the review. The target population was children and young people under 25 years old. Level of participation was categorized according to Shier's Pathways to Participation Model.

Results: The review showed that participatory approaches were most often used in the development of interventions in school settings and in community and healthcare settings and on issues concerning support in lifestyle or in managing illness or disease. The level of participation varied from children and young people taking part just as active informants, through stages of greater participation both in quantitative and qualitative terms, to children and young people becoming an active agent involved as a co-researcher where the research process was shaped by views of a higher level of mutuality. Most of the studies were categorised at a medium level and only three studies were judged to involve the children and young people at the highest level.

Conclusions: This scoping review showed that work remains in enabling children and young people to influence the development of interventions targeting health and well-being. In relation to level of sustainability in the interventions, it is relevant that goals, strategies and processes are formulated by those who can gain from the interventions. Participatory approaches aiming for a higher level of participation where children and young people work together with the researchers in partnerships are thus warranted.

Keywords: Children, Intervention, Participatory approach, Scoping review, User involvement, Young people

\footnotetext{
* Correspondence: Ingrid.larsson@hh.se

School of Health and Welfare, Halmstad University, Box 823, S-30118 Halmstad,

Sweden
}

(c) The Author(s). 2018 Open Access This article is distributed under the terms of the Creative Commons Attribution 4.0 International License (http://creativecommons.org/licenses/by/4.0/), which permits unrestricted use, distribution, and reproduction in any medium, provided you give appropriate credit to the original author(s) and the source, provide a link to the Creative Commons license, and indicate if changes were made. The Creative Commons Public Domain Dedication waiver (http://creativecommons.org/publicdomain/zero/1.0/) applies to the data made available in this article, unless otherwise stated. 


\section{Background}

A growing body of literature and health research policies has, in recent decades, emphasized the importance of more participatory approaches in health research that include views, knowledge, experiences and actions from those who are in focus of the research. Similarly, it has been highlighted that children and young people should be involved in co-creating new knowledge [1-6]. Although participatory approaches have user involvement in common, they differ in terms of the explicit guidance on how to actually involve and engage children and young people in health research $[7,8]$. Many factors can challenge children's and young people's involvement, such as an underestimation of children's competence to participate in research [1], attitudes that child involvement might adversely affect the quality of the research [9-11] or fear that participation might harm the child [2, 9-11]. As a result, children are usually merely involved as subjects in research and not as active research partners [3, 5]. Most health research for children and young people is thus primarily based on the involvement of parents, caregivers, and other stakeholders. However, such stakeholder perspectives cannot replace the qualities that come with genuine participation by the children and young people themselves [3, 5, 12, 13].

Children as social actors were emphasized by the Convention on the Rights of Children in 1989 [14]. The principles of the convention are relevant for how researchers relate to children's participation and serve as a standard for how integration and assessment of children's participation in research should be planned and assessed. Increased emphasis in health research on the need to develop solutions to improve the health of children and young people's thus also requires that children are viewed as important partners in co-creating such solutions [15], providing both relevant knowledge for the design of solutions and guidance and planning for evaluation and implementation in practice [16]. When co-production approaches are used in health research, they increase the likelihood of developing more effective and efficient interventions that more precisely targets health and well-being issues among children and young people. This, however, requires a shift in the way research is designed, communicated and performed [17] and necessitates that children and young people are recognized as experts with the capability of contributing with unique experiences and knowledge [8]. However, it is difficult to classify and evaluate health research in ways that shows both the level of children and young people's participation during the research process and its relation to the impact of the research and translation into practice [18]. In the application of participatory research it is important to distinguish three overall stages of participation [6], that differ both in principle and in the way they can be translated into practical implementation in health research. These stages are; nonparticipation, consultative participation, and collaborative participation. In the stage of nonparticipation, children are either not involved at all or are involved in ways that have no real impact on the research or that give a false semblance of partnership and sharing of power. At the stage of consultative participation, adults acknowledge the expertise of children and involve them in sharing their views and experiences, primarily through interviews or questionnaires. However, such approaches are neither giving the children control over the focus of the research or influence over the analysis or interpretation of data. At the collaborative stage, children are not only involved as experts but also take part at various degrees in initiation, planning, analysis and dissemination of the research. The partnership between the researcher and the children at this level is based on both trust and shared decisions [6]. Models that describe how participation can occur at different levels of intensity and quality are valuable as benchmarks in the planning of research and as guidance for evaluation of participation. Hart's Ladder (1992) [19] adapted from Arnstein's work [20] and Shier's Pathways to Participation [21] are commonly used models when developing and evaluating children and young people's participation in projects. Both models can be suitable when evaluating children and young people's level of participation in research. In this scoping literature review, however, we decided to use Shier's model [21] based on this model providing a more practical framework for planning and evaluating children and young people's participation in practice. Shier's model combines five levels of participation and three stages of commitment at each level describing the child's transition from a passive actor towards having a partnership position where the child and the adult have equal positions [21].

Despite the increasing expectations that children and young people are involved as partners in health research, and despite that models for discriminating between different levels of participation and how to tackle challenges to participation are available, there is still considerable uncertainty among researchers about how to optimally provide opportunities for involving children and young people in health research. The aim of this scoping review was thus to systematically map recent research involving children and young people in the development of interventions targeting issues of health and well-being. The specific objectives were to; a) identify the extent of recent research using participatory approaches to involve children and young people in the development of interventions targeting health and wellbeing, b) grade the level of participation in such participatory approaches, and c) identify areas for further research. 


\section{Methods}

\section{Study design}

An interpretative scoping literature review, based on the framework of Arksey and O'Malley [22], was chosen for the study design. A scoping review contributes a systematic knowledge synthesis in a defined area based on an explorative research question with the aim of mapping key concepts, available evidence, and gaps in the research [23]. Scoping reviews are useful for summarizing and describing data from a wider range of fields and disciplines and for identifying gaps in the literature, and thus the quality of the studies are not the focus of the evaluation. To enable replication and strengthen methodological rigour, this study follows the five-stage methodological framework of Arksey and O'Malley [22]; identifying the research question, identifying relevant studies, study selection, charting the data, and collating, summarising and reporting the results.

\section{Identifying the research question}

The core question in this scoping review was: In which areas and to what extent were children and young people involved in the development of interventions targeting children and young people in health and well-being. The definition of children, in this scoping review, was a person under 18 years old, which is in line with The United Nations Conventions of the Rights of the Child [14], while young people are referred to a person between 15 and 24 years old, in accordance with The United Nations [24].

\section{Identifying relevant studies}

The evidence was searched by way of electronic databases, reference lists, hand-searches of key journals and contact with existing networks. With the help of experienced librarians an electronic database search incorporating Academic Search Elite, CINAHL, ERIC, Medline, PsycInfo, Sociological Abstracts and SportDiscus was conducted in December 2014, updated in April 2015 and finally updated in December 2017. Different techniques and terms were used for expanding and narrowing searches, including search tools such as medical subject headings (MESH), Boolean operators and Truncation. Single and combined search terms included the key words: "child", "adolescent", "participate", "participation", "collaboration", "involve", "involvement" and "intervention". Relevant publications were defined as any empirical peer-reviewed paper. No limitations were set in terms of the publications date, as no previous review focusing on children and young people's participation in the development of interventions had been performed. English was chosen as the language for the database search, as it is the most commonly used language in scientific journals. Inclusion criteria were: articles with children and young people under 25 years old; articles in which children and young people participate in one or more levels of the development of an intervention aimed at children and young people in health and well-being. Exclusion criteria were: articles in which children and young people were only participants in an intervention or evaluated an intervention.

\section{Study selection}

The searches identified 4458 articles, which were catalogued in EndNote ${ }^{\odot}$. Duplicates $(n=218)$ were removed by automation, supplemented by manual checking. An initial scan of title and abstracts identified large numbers $(n=3857)$ of irrelevant studies. A total of 383 articles were retrieved and read in full text by the authors. Seventy four studies were identified as potentially relevant after an elimination process based on the inclusion and exclusion criteria. These articles were reviewed by three of the authors (IL, CSN, IMC) and by consensus a final decision was made on which articles to include. The development of a particular intervention was sometimes described in a number of articles and in these cases only one of these articles describing the intervention was included in this scoping review. In some articles, when the target group for the intervention was children and young people, the development of the interventions was poorly described, but it appeared that the researchers developed the intervention together with parents, health professionals or other adults. Articles were excluded if children and young people participated in the implementation of an intervention or in the evaluation of interventions with the specific aim of modifying an intervention designed by the researchers. A total of 41 articles were finally included in the scoping review (Fig. 1).

\section{Data charting and collation}

The authors created a data charting form which included: reference (author, year), country, key aims, number and age of children and young people, type of intervention, aim of participation, and finally in which parts of the developmental process the included participants were involved. The authors (IL, CSN, IMC) first extracted data independently and then met to determine whether the data extractions were consistent with the aim of the study and the research questions (Table 1).

\section{Collating, Summarising and reporting findings}

In order to grade the level of participation in the analysis, we summarised and categorised the data in accordance with Shier's Pathways to Participation Model [21]. This model includes the following five levels of participation:

Level 1, Children and young people are listened to, requires that researchers listen to the children and 


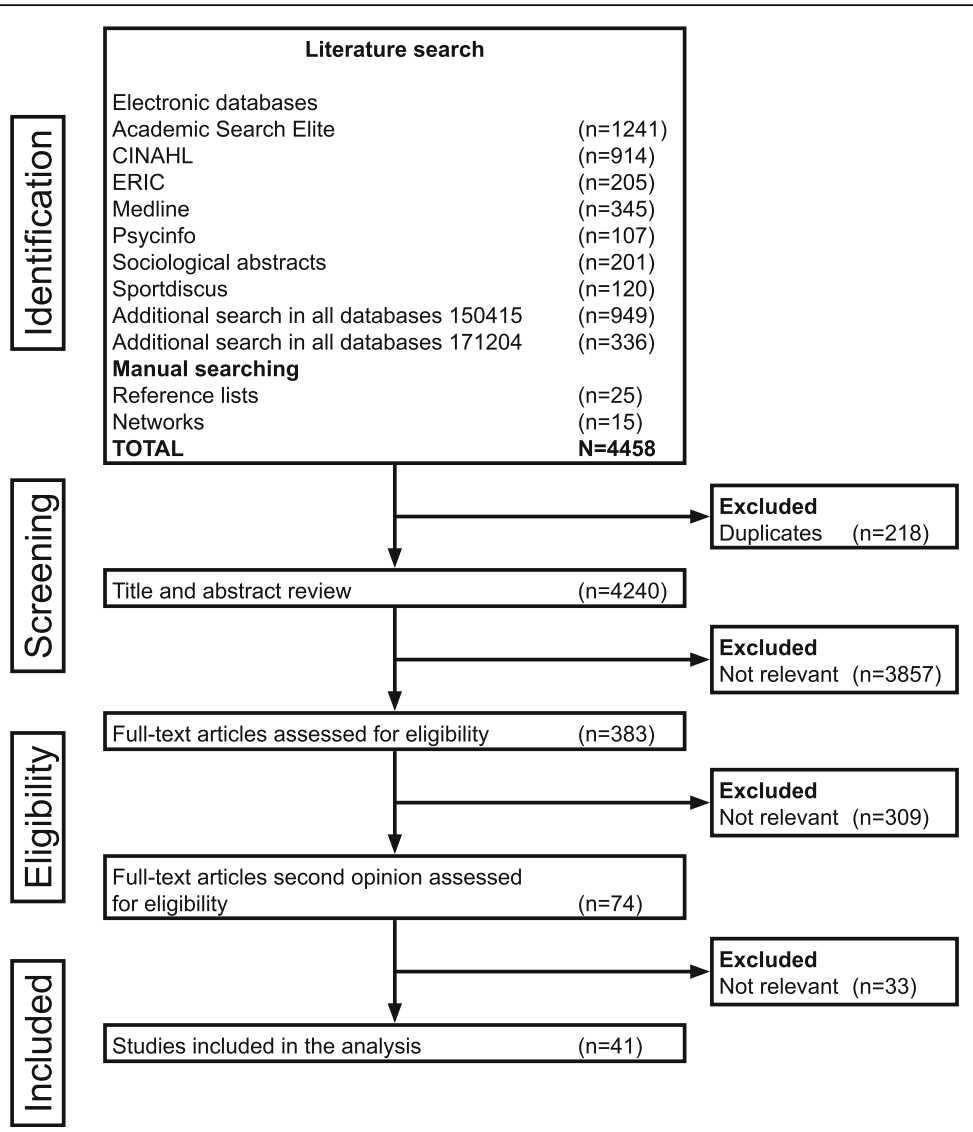

Fig. 1 Flowchart of literature search and selection

young people when the children and young people take the initiative to express their views. In this stage the children and young people can thus be seen as responsible for taking active initiatives in order to participate. At level 2, where children and young people are supported when expressing their views, the initiative and responsibility is moved to the researcher who has to find and facilitate ways for the children and young people to express their views and by this enable the children and young people's participation. At level 3, the degree of participation is extended and children and young people's views (explicitly or non-explicitly expressed) are taken into account. This level is distinguished from level two in that children and young people's views are not only listened to or asked for but are also seriously taken into account with the aim of having influence.

At level 4, children and young people are involved in decision-making processes. This level and level 5, where children and young people share power and responsibility in decision-making are characterised by a successive transition from children and young people seen as consultants to a stage where they obtain a position of power. These are characterised by the willingness of researcher to share or give up their power in favour of children and young people's contribution. In moving up the levels $(1-5)$ the model describes the children or young people moving from being a passive informant to an active agent towards a partnership position where researchers and children or young people are in an equal position.

In order to categorise the level of children and young people's participation, the included studies were judged overall based on a) quantitative aspects of participation i.e. number of activities or stages in the developmental process that included children and young people and b) qualitative aspects i.e. to what extent such involvement was based on reciprocity concerning influence, power and decision-making in the developmental process. In order to strengthen the validity in this process the authors (IL, CSN, IMC), who were multidisciplinary, independently analysed the children and young people's level of participation in each intervention in accordance with Shier's five-stage framework [21]. The authors discussed and compared their analysis and level of participation in the articles until consensus was reached. 


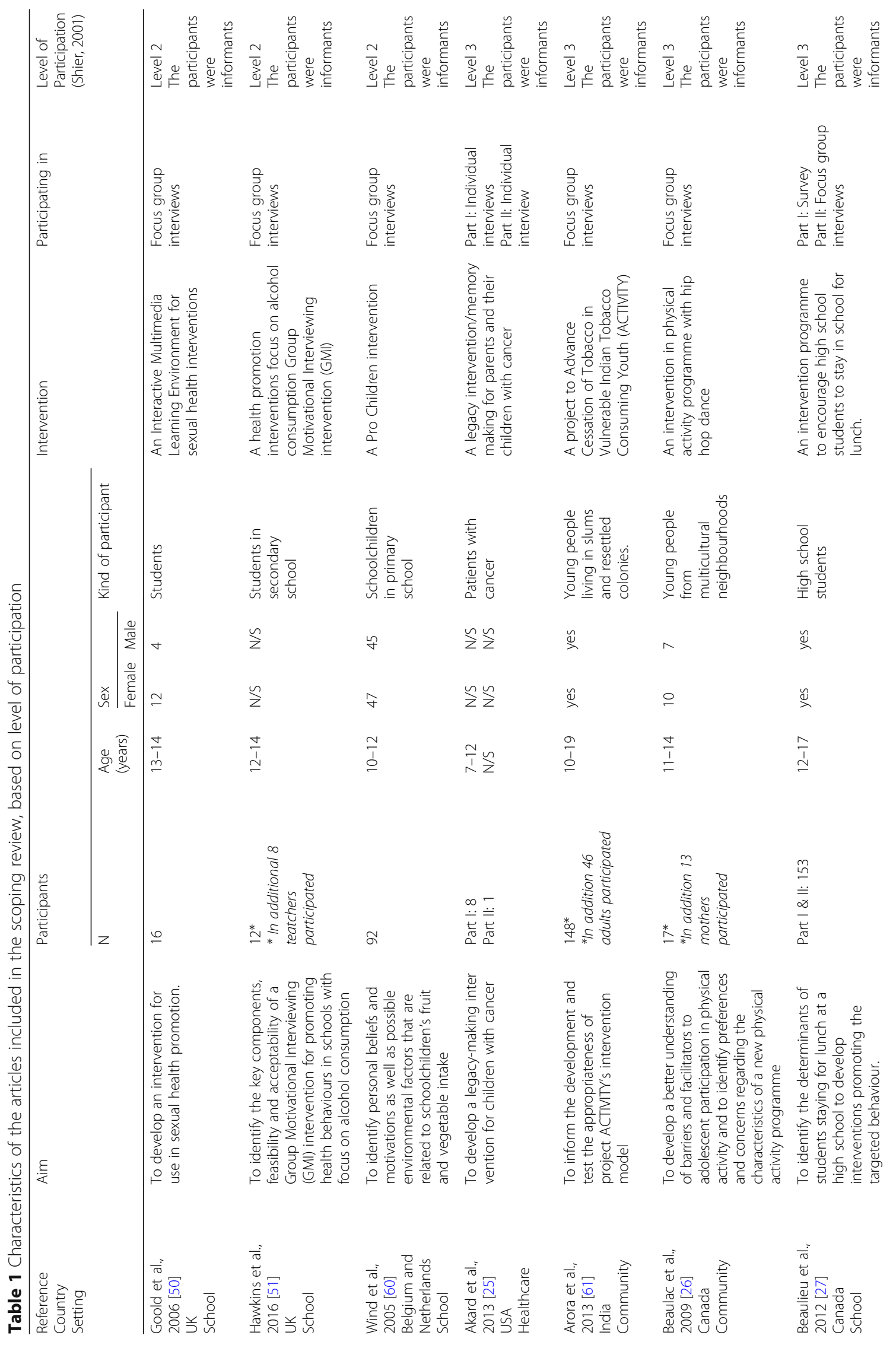




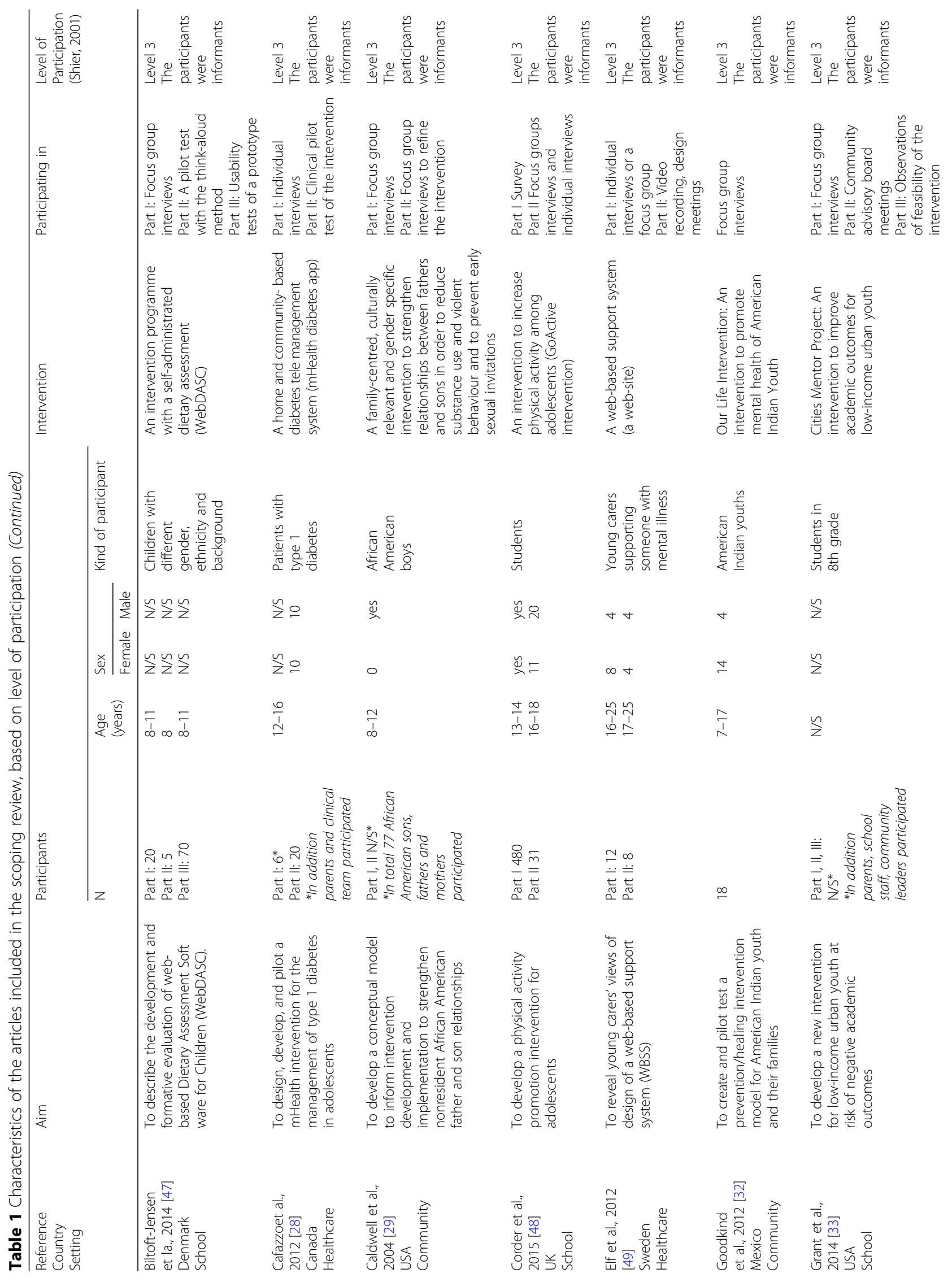




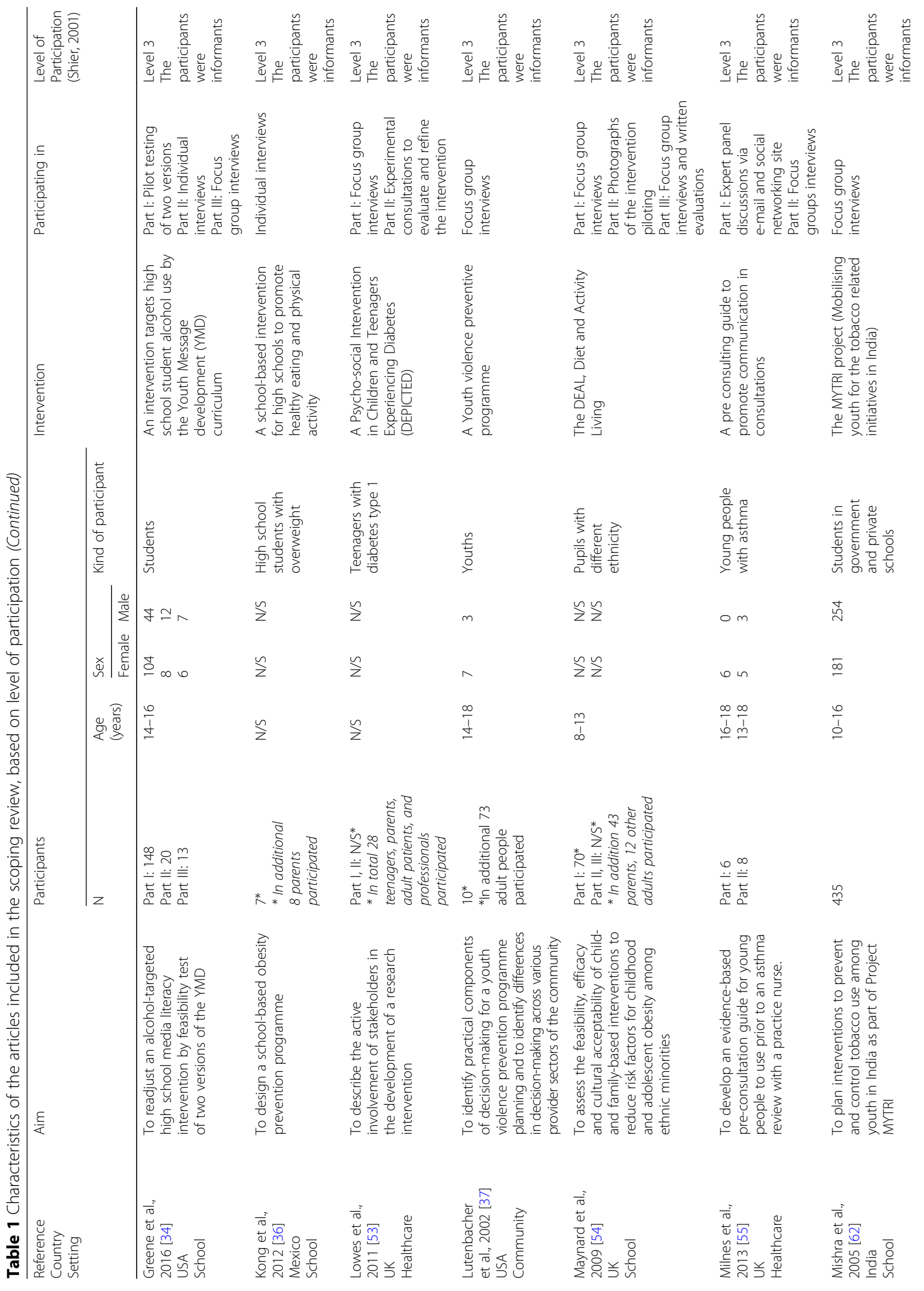




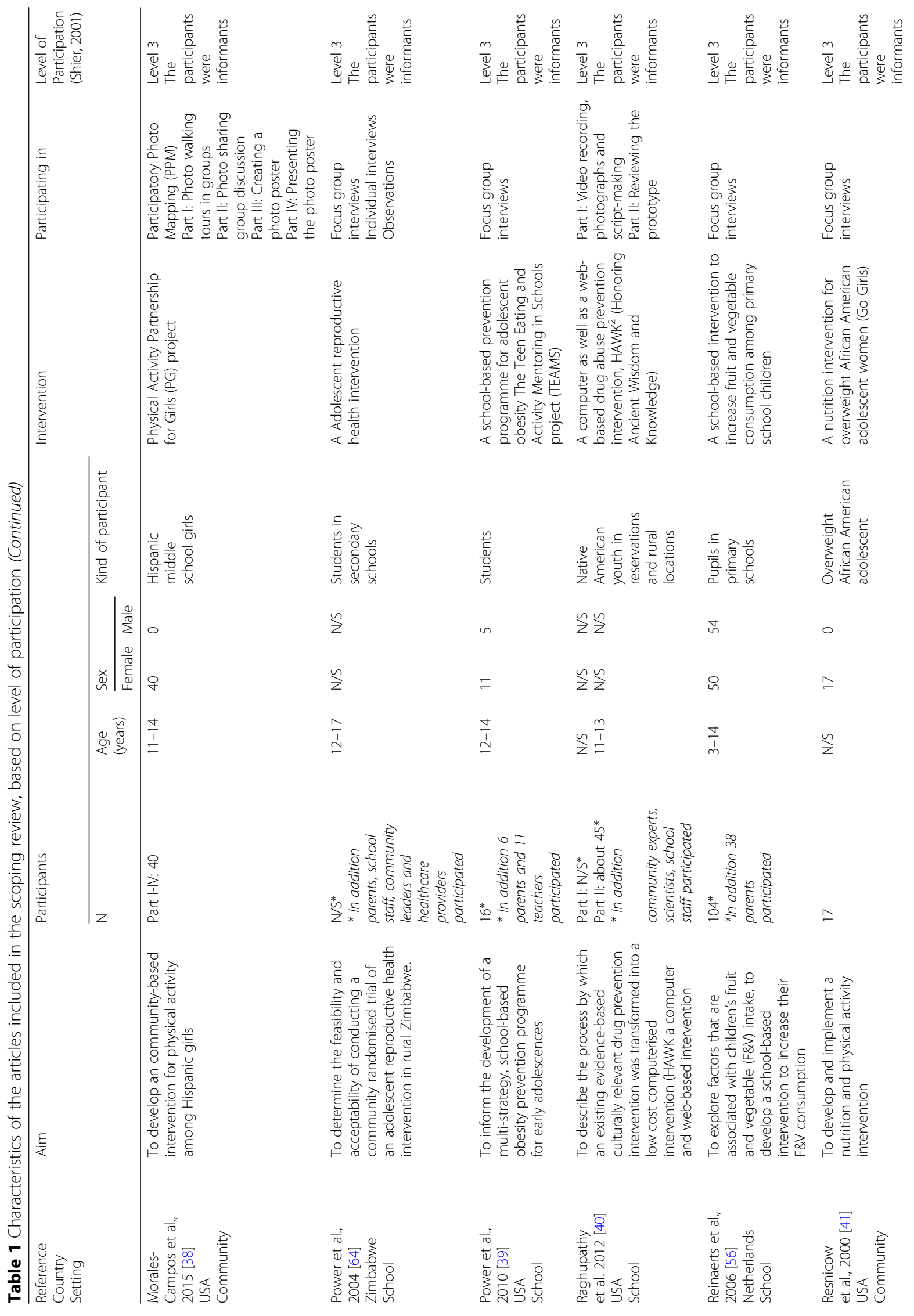




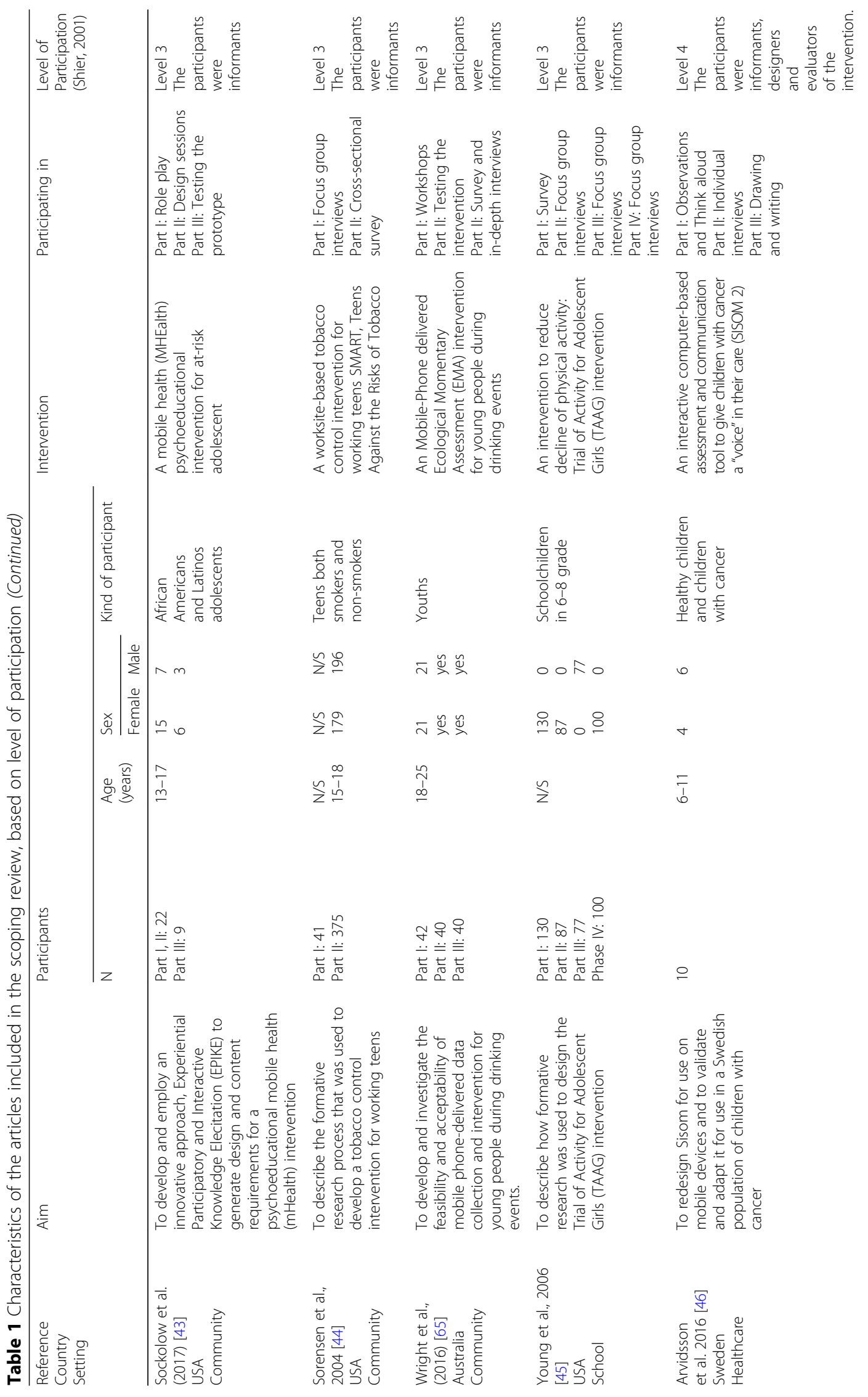




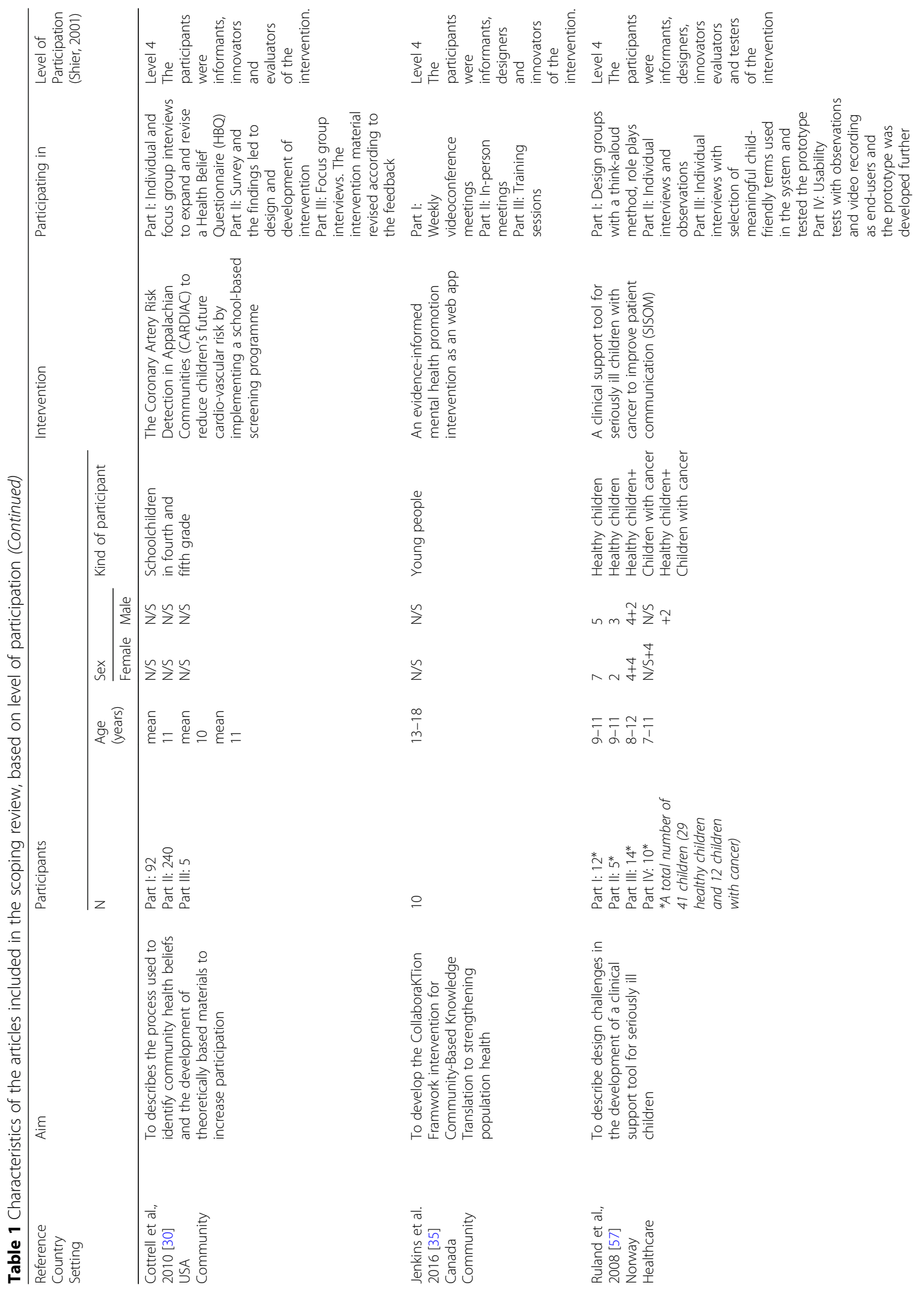




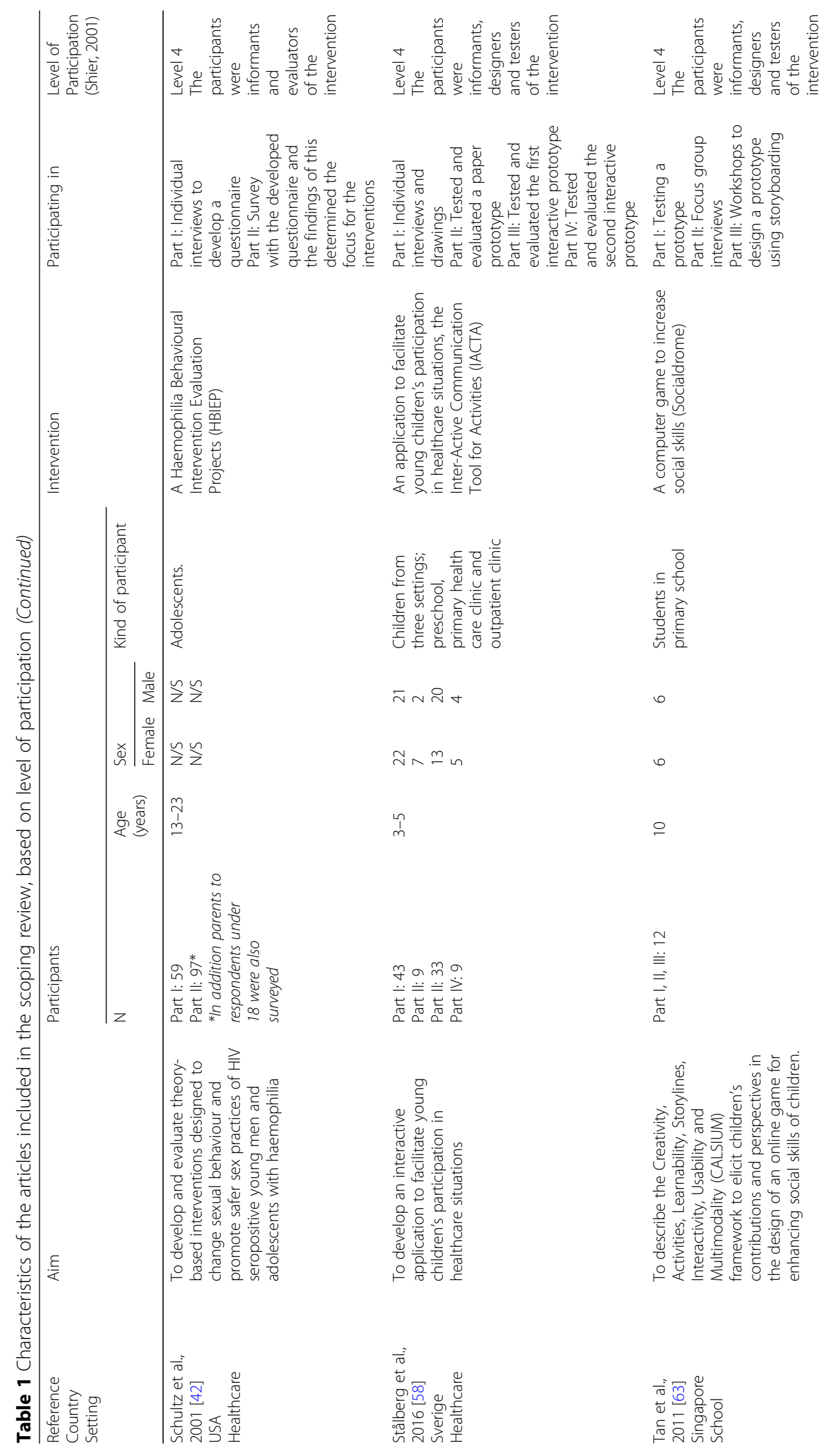




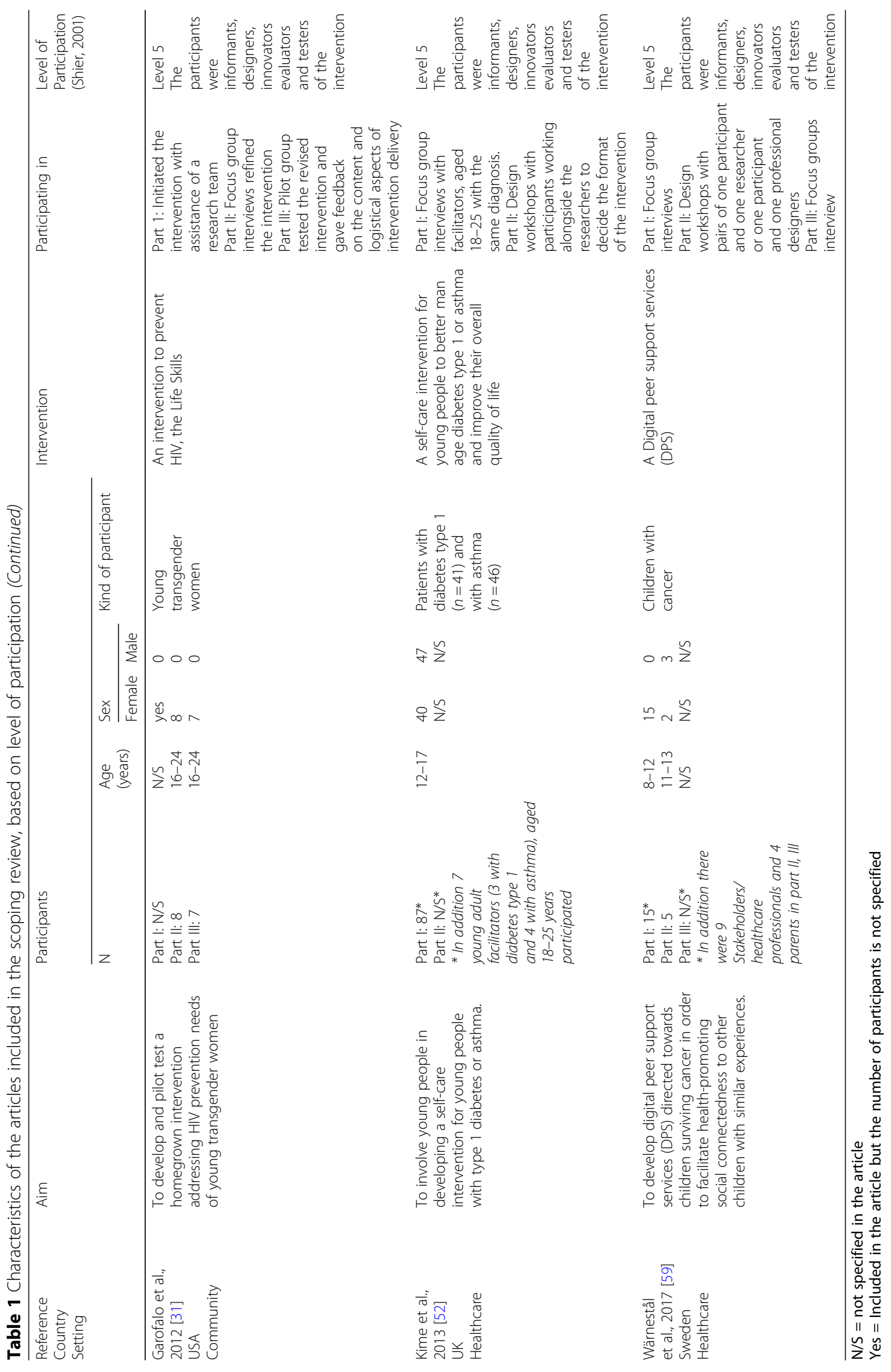




\section{Results}

Our overall aim with this scoping review was to grade children and young people's participation in the development of interventions. To enable this goal and to gain an overall view of the field we needed to make sense of our complex findings. Therefore, in addition to displaying the number of articles, we also found it useful to map the research fields according to general characteristics of the included articles such as the settings and countries were the research took place. It was also considered of interest to focus on the interventions made and the methodological characteristics of the included articles, i.e. the actions agreed as the result of the research and the types of practices that were needed to promote children and young people to participate in the research field. Furthermore, we used Shier's [21] model to analyse and grade our findings according to the children and young people's level of committed participation in the research. To allow this view of the field to be seen, the findings are illustrated in three areas; general characteristics of the included articles, methodological characteristics of the included articles and children and young people's level of participation in the development of interventions in the included articles, with a combination of texts, tables, and figures.

\section{General characteristics of the included articles}

There was a total of 41 articles included in this scoping review. These were published between 2000 and 2017 and were from different parts of the world. A majority of the studies, 21, were conducted in North and Central America [25-45] and 15 in Europe [46-60]. A small minority of the studies were thus undertaken in the other continents, Asia [61-63], Africa [64] and Australia [65]. The participants in the included articles varied in age between 3 and 25. Four of the included studies did not, however, explicitly declare the participants' age and instead used terms such as teenager or teens [44,53], adolescents [41] and students [36]. Another way of expressing the participants' "age" was to refer to which grade or school system the participants were in when the research took place [33, 45].

Furthermore, the included articles in this scoping review varied according to research settings. We categorised three broad settings, 13 were conducted in community settings [26, 29-32, 35, 37, 38, 41, 43, 44, 61, 65], a further 11 in healthcare settings [25, 28, 42, 46, $49,52,53,55,57-59]$, and 17 in school settings [27, 33, $34,36,39,40,45,47,48,50,51,54,56,60,62-64]$.

The reviewed articles had two different foci for the developed interventions, support for lifestyle changes and support in managing illness and disease (Fig. 2). However, both of these foci were supporting interventions concerning health and well-being. The main areas in 30 articles were supportive lifestyle interventions and concerned: a healthy diet and obesity [27, 36, 39, 41, 47, 54, 56, 60], physical activity $[26,36,38,39,41,45,48,54]$, substance abuse such as, alcohol, tobacco and drug use $[29,34,40,43,44,51,61$, $62,65]$, sexual and reproductive health $[29,31,42,43,50$, 64], violence [29, 37], stress [33], social skills [63], health beliefs [30] and mental health promotion [35]. In addition to lifestyle issues, eleven of the articles considered issues that supported children and young people with their illness or disease. These were supportive interventions to manage healthcare situations [58], support children and young people with cancer $[25,46,57,59]$, diabetes $[28,52,53]$, mental illness [32, 49], and asthma [52, 55].

\section{Methodological characteristics of the included articles}

Most of the studies included in the scoping review have used interviews as a data collection method to give a voice to the participants. Focus group interviews was the most common data collection method [26, 27, 29-34, $37,39,41,44,45,47-56,59-64]$ while other studies have used individual interviews $[25,28,30,34,36,42$, $46,48,49,57,58,64$ ] with children and young people. However, seven of the studies reported including both interviews and surveys to involve the children and young people's views in the development of the intervention $[27,30,42,44,45,48,65]$. As a supplement to these more traditional data collection methods there were also research designs that included a range of innovative methods, such as video recordings $[40,49,57]$ photographs $[38,40,54]$ drawings and texts $[46,58,59]$ advisory boards [33], e-mail and a social networking site [55], observations [57, 64], script-making [40, 43], storyboarding [63], active and spontaneous role play [43], and videoconferences and in-person meetings [35].

The interventions were sometimes tested for feasibility and usability and a wide range of methods were used, including face validity [25] think-aloud methods [43, 46, 47, 57], interviews [31, 32, 34, 65] and observations [33, 57]. Written feedback [27, 31, 34, 54], workshops [52, 59, 65] and a mobile survey [65] were also used.

\section{Children and young people's level of participation in the development of interventions}

The articles were also graded according to the children and young people's level of participation in the development of the interventions. We used Shier's model, which contains five levels of participation [21], as a framework to map our findings (Fig. 3).

All studies regardless of design were graded from level one to level five. However, due to the inclusion criteria in this scoping review, where children and young people had to be involved in the development of an intervention, all the included articles met the criteria for the second level according to Shier's model [21]. Level one is thus not further described in the findings section. There was, however, 


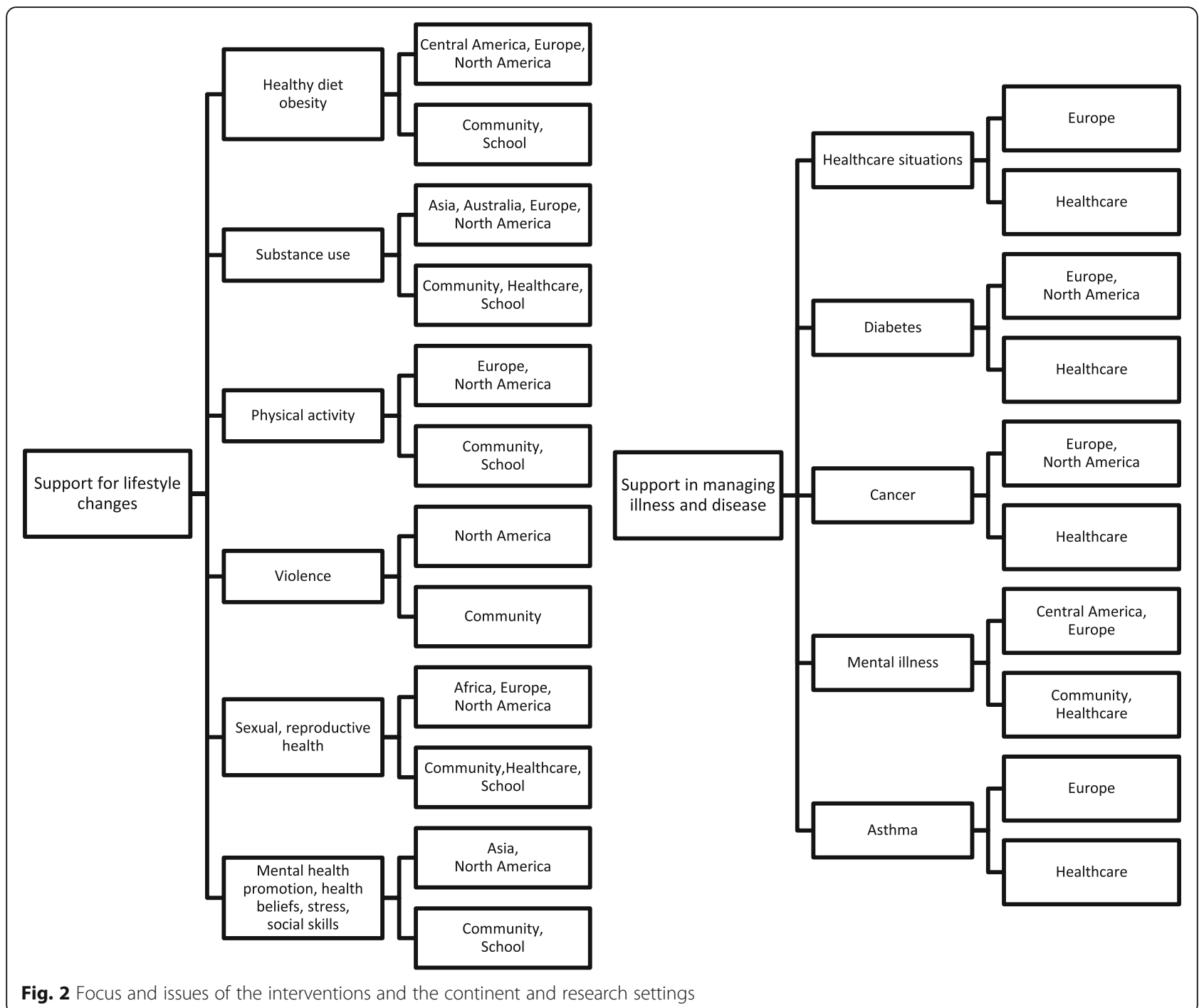

a variation in how clearly and detailed the authors described the research process as to how the voice of the children and young people influenced the development of the interventions.

The findings showed a variation in the articles in terms of the children and young people's level of participation. Furthermore, this participation varied both in quantitative and qualitative terms from just being an active informant to an active agent taking part in more steps in the research process as a co- researcher. When the research process was shaped by views of a higher level of mutuality the participants were enabled to share power and responsibility in the research process.

\section{Level 2. Children and young people are supported to} express their views in the development of interventions

This was the lowest level for participation found in this scoping review. The children and young people simply had a participatory role as informants in the research process at this level. Only three articles $[50,51,60]$ in this scoping review were analysed as only meeting the criteria for level two. The low rating for these articles was due to the researchers only describing that they had supported the children and young people to express their views and that they had facilitated ways for listening to the participants. The researchers did not, however, describe how the information was used. Furthermore, these articles only stated that the performed focus groups were to inform the development of an intervention but the researchers did not explicitly describe the ways in which the information affects the intervention $[50,51,60]$. It is unclear if the participants' voices were taken into account or not thus leaving the reader with unanswered questions.

\section{Level 3. Children and young people's views are taken into account in the development of interventions}

The vast majority, in total 28 , of the included scoping-review articles, met the criteria for level 3 [25-29, 


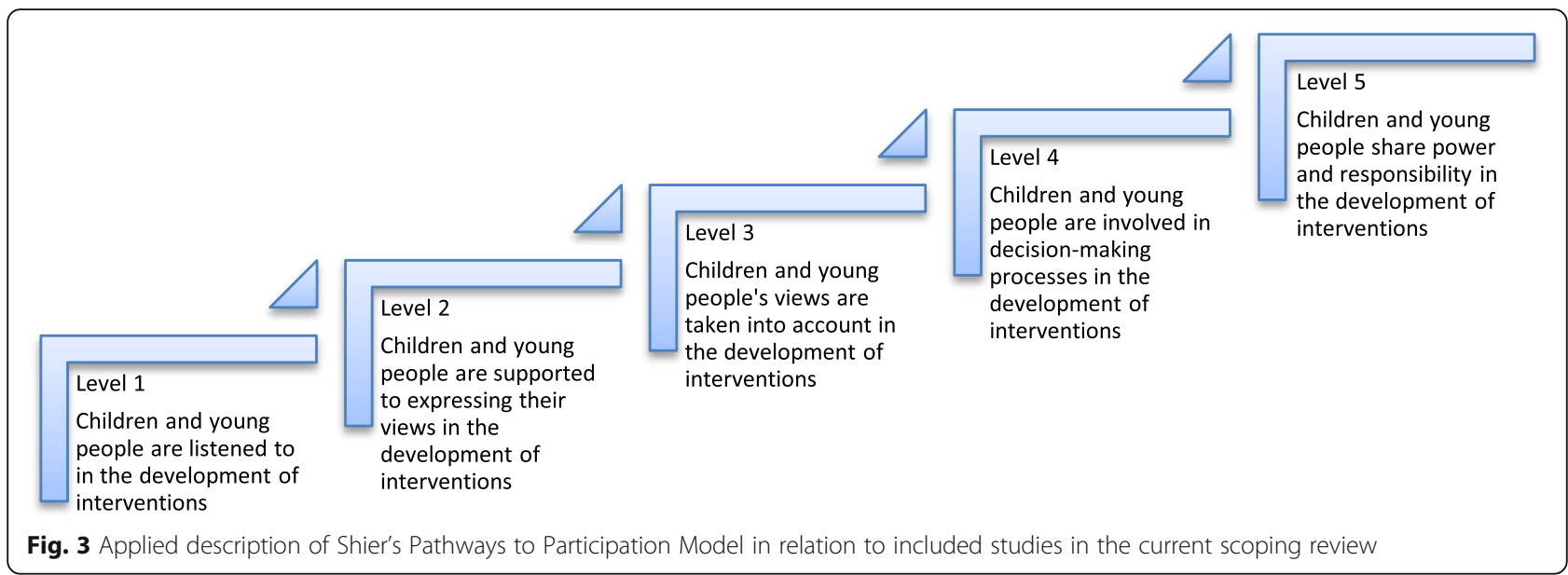

32-34, 36-41, 43-45, 47-49, 53-56, 61, 62, 64, 65]. The distinction between this third level and the previous one was that the children and young people's views were not only asked for and listened to, but their voice was also seriously taken into account with the aim of influencing the further process of the development of the intervention, and that this was explicitly expressed in the article.

Expressions such as; "helped to develop the intervention", "guided" or "informed" were used to describe the ways in which the children and young people's views were taken into account at this level. We can therefore conclude that the children and young people were listened to and that they also had an impact on the development of the intervention. However, the words that explain the participatory part of the development are relatively vague leaving the reader uncertain as to how much of the information was used by the researchers.

\section{Level 4. Children and young people are involved in the} decision-making processes in the development of interventions Seven of the 41 articles in this scoping review were considered to fulfil the criteria for the fourth level of participation [30, 35, 42, 46, 57, 58, 63]. To be able to attain this assessment the article had to explicitly describe that the researchers involved the participants in the decision-making process when the intervention was developed. This implies that the children and young people's voice has an even greater level of importance and is taken into consideration. It is not sufficient for this level of participation that the researchers themselves choose which part of the information is to be used in the development. The children and young people's voices need to instead be taken more seriously and there needs to be a successive transition, from just seeing the children and young people as consultants to a position where they have a much more important and extended position in the development of the intervention. In the articles at this level, the researchers explicitly expressed that the participants; "developed the design", "determined the development" or "accounted and contributed to the design" as well as being "central collaborators" and "co-designers".

\section{Level 5. Children and young people share power and responsibility in the development of interventions}

Only three of the included articles managed to reach the highest level in Shier's model of participation [31, 52, 59]. Level 4, children and young people are involved in decision-making processes, and level 5, where children and young people share power and responsibility in decision-making are characterised by a successive transition from children and young people as consultants to a stage where they obtain a position of power. These are also characterised by the willingness of researchers to share or give up their power in favour of the children and young people's contribution. In moving up the levels (1-5) the model describes the child or young person moving from a passive informant to an active agent towards a partnership position where researchers and children hold an equal position.

The three studies that achieved this level were more characterised by a willingness from the researchers to share the power to influence the developing process with the participants. The research idea in the study by Garafolo et al. [31] originated from the participants themselves. Young transgender women created the intervention with assistance of the research team. The feasibility of the intervention in this study was then tested and evaluated with the participants and their further suggestions were used to refine the intervention. The researchers and the participants in the study by Kime et al. [52], worked "side by side" at different stages of the research process. Finally, in the study by Wärnestål et al. [59], the researchers explicitly named the participants as "designers" and "innovators" and described the co-creation in 
developing the intervention during the whole process together with the children. This demonstrated that the children and young people had an extended role where they could influence the development. The designation as a designer also proved that the researchers were willing to share a certain amount of power over the developmental process. In addition, the participants were included in several of the research steps as informers, testers, evaluators and finally as informants about the usability of the intervention.

\section{Discussion}

The need for and operationalization of more explicit participatory approaches in research where participants actively take part throughout the research process has increasingly been discussed. This review provides an overview of research during 2000-2017 with a focus on children and young people's level of participation in research aiming at developing health and well-being interventions. Results from research from both the health and social sciences were included, which to our knowledge has not previously been performed. The main findings showed that the explicit level of participation in the included studies varied greatly, both in quantitative and qualitative terms, and that the designs and the methodologies used in order to increase the level of participation were generally poorly described. Even though studies reported an ambition to increase children and young people's participation in the research process, actually doing so was more seldom supported by the results. The participants only took part as informants in a majority of the studies $[25-29,32-34,36-41,43-45$, $47-51,53-56,60-62,64,65]$ and surprisingly few reached the higher levels of participation $[30,31,35,42$, $46,52,57-59,63]$ in Shier's model [21]. These findings were somewhat unexpected since approaches, in which representatives from the target group formulate the needs and goals of an intervention, increase the level of sustainability of the outcomes $[5,66]$.

In line with the work of Reich et al. [67], the studies that reached the fourth $[30,35,42,46,57,58,63]$ and the fifth [31, 52, 59] levels appeared to be less expert-driven. Furthermore, a specific feature of the studies on the fifth level was that the children and young people were co-researchers in all parts of the development process. For example, participants were described as designers or that they were working alongside the researchers. In one of the studies [59] working pairs of participants and researchers or professional designers were formed. These types of descriptions indicate a higher level of partnership mutuality and that a transfer of power, from researchers to participants, was facilitated and had possibly taken place. Broström maintains that research needs to include the participants at all stages of the process if the participants are to be recognised as co-researchers [68]. Consequently, participants also need to have an influence on the research questions and development of the interventions from the start to ensure that the intervention responds to their needs and takes their specific contextual situation into account [69]. It was only in the study by Garafolo, in this review, where it was reported that the participants had an opportunity to influence the intervention from the conceptual stage [31].

In spite of having participatory approaches as a common denominator, it was notable that the descriptions of the methods varied considerably as to how these approaches were carried out throughout the research process. Several studies had inadequate descriptions of the methods used and were therefore excluded at an early stage. Moreover, information concerning design and methodology were lacking or incomplete in some of the studies that met the criteria for inclusion. This is an important result since a more accurate and thorough methodological description could help revealing which factors, conceptions and assessments influenced the participatory approach in the reviewed studies. Moreover, the information could have been significant for the understanding of how different mechanisms in the research process were influenced by contextual factors as well as how they in turn informed the results of the developed intervention [70].

Levels of possible and expected participation will by nature vary with the age of the children as well as with their knowledge and experience of a certain issue or situation. Since previous studies have pointed out that children's capabilities are often underestimated [1, 4] it was particularly interesting, that one of the studies reaching level four, involved children as young as three to 5 years of age [58]. Appropriate and mixed data collection strategies are necessary for successful inclusion of children and young people as active research participants [71] and indeed those studies that reached the highest level of participation used a variety of data collection strategies. In addition to interviews or surveys, the most common methods of data collection for studies at higher levels of participation, were methods where children could be active and express themselves in other ways than verbal ones [30, 31, 35, 42, 46, 52, 57-59, 63]. Such methods could for example include drawing, painting, writing [72], theatre [73], photography, filming [74] workshops, storytelling using software and digital tools, and mapmaking [73]. Using such methods at different stages in the research process does not in itself guarantee a participatory approach $[74,75]$, but they can promote the participants' sense of control and thereby enable them to take a more active part in the research process [73]. Methodology in itself can thus push a traditional top-down research paradigm in a more egalitarian 
direction [73] and increase credibility and reduce potential biases by triangulating different data sources [76].

The scoping review showed that participatory approaches in the development of interventions were most often used in school settings and aimed at supporting lifestyle issues or managing illness or disease [27, 33, 34, $36,39,40,45,47,48,50,51,54,56,60,62-64]$. None of the included studies focusing on school settings reached the highest level of participation and only one study reached level four [63]. It is possible that the school context, with its traditional structure of power, is preserving a top-down approach in the development of school interventions. In addition, researchers, based on their own experience, might be confident in having sufficient knowledge about the school environment and children and young people's daily lives and how interventions could best be put forward [67]. However, such attitudes can have a negative impact on utilizing the potential of the school as an arena for health interventions that are co-developed in partnership with the children, strategically to prevent the occurrence of ill health and tactically to promote the health of vulnerable groups or individuals with special needs.

In conclusion, researchers often advocate a participatory approach in which children and young people are seen as credible informants on interventions aimed at improving their health and well-being. However, this scoping review has showed a somewhat ambiguous result concerning implementation of this understanding in research practice. In order to recognize children and young people's capabilities as active contributors instead of passive recipients of researcher-driven interventions, a consistency between the theoretical understanding of a participatory approach and what is undertaken in research practice in developing health interventions together with the target group is needed.

\section{Strengths and limitations}

Despite a focus on a broad research field and a fairly wide range of publication years, only 41 articles met the inclusion criteria. In an effort to provide clarity and focus for the inclusion and exclusion criteria the research group attached great initial importance to discussing concepts linked to the aim, such as "what action is required to be called an intervention" [77, 78]. Furthermore, additional methodological rigour in the inclusion process included two of the authors independently reading the full text articles. If uncertainty occurred related to article selection, the third author also read the article and a final inclusion decision was then reached in consensus [77]. As an aid to transparency and reproducibility a flowchart and additional text from the search process were included in the method section.
Efforts were made to do more than just map and describe the characteristics of included studies by using Shier's model [21] as an analysis of the levels of participation. The model has been used in enhancing children and young people's participation in decision-making in society but to our knowledge the model has not been used before in grading of children and young people's participation levels in the development of interventions in health and well-being. However, we consider the model to be useful in order to map and clearly illustrate at which level children and young people are involved in these research studies and thus pinpoint the state of knowledge.

The search process in our study is, however, subjected to certain limitations since our strategy was restricted to health, social science and educational databases. Although experienced librarians performed extensive literature searches in several research databases resulting in a large number of articles, it is possible that relevant studies were missed. We have selected original research articles, which thus did not include reviews or grey literature that may have contained studies that could contribute understanding to this topic. Despite only original research articles being included in this scoping review, there is a limitation since scoping reviews do not typically include a quality assessment of included studies [77-79]. This review may also have been limited by restricting the search to English articles as it is the most commonly used language in scientific journals [78]. Moreover, we may lack full knowledge of existing international networks in the research area.

A further limitation could be said to exist in the potential risk for the validity of the grading levels of participation. Even though, the study's research team was multidisciplinary, they all shared the same geographical and academic context. Moreover, based on the variations in journal requirements, it should be acknowledged that these requirements might be lead to publication bias in terms of how the concept of participation was presented.

It was not possible to further discuss country-specific differences in relation to participatory research approaches as the relatively small total of 41 studies were from a total of 13 different countries. Questions regarding differences between countries and contexts in attitudes concerning to what extent children and young people can be, and are involved in the development of interventions, were not part of the aim for this study but are recommended to be included in future research.

\section{Conclusions}

This scoping review showed that work remains in enabling children and young people to influence the development of health interventions. Many studies were keen to discuss the importance of taking children and young people's views, experiences and suggestions into account 
when developing interventions. However, relatively few invited these children and young people to share power in the design, implementation and analysis of the research or as partners in the process of developing the intervention. Participatory approaches aiming for a higher level of reciprocity where children and young people work together with the researchers in partnerships are thus warranted. Such studies also need to carefully describe the methods used in the collaboration with children and to use models, such as the one described by Shier, in their description of how and to what extent the children were actually involved. Only then will it be possible to proceed from describing children's participation from a theoretical point of view to confronting such argumentation based on previous research. Examples and experiences from further research is a necessity for being able to elaborate on what participation actually means and which level of participation that is most appropriate given a certain context or target group. Further research is also needed to investigate to what extent there is a more beneficial outcome from the interventions, depending on whether the children are involved in the development of the intervention or if the intervention is developed solely by the researchers.

\section{Abbreviations}

CINAHL: Cumulative index to nursing and allied health literature; ERIC: Education resources information center; MESH: Medical subject headings; Psyclnfo: Psychological information database; UN: United Nations

\section{Acknowledgements}

This study was supported by internal grants from the Centre of Welfare, Health and Sports at Halmstad University.

\section{Funding}

This research received no specific grant from any funding agency in the public, commercial, or not-for-profit sectors.

\section{Authors' contributions \\ All authors (IL, CSN, PS, JN, IMC) made significant contributions in the scoping review, by together identifying the research question and design the scoping review. (IL, CSN, IMC) identified and selected relevant studies, charted the data, and collated, summarised and reported the results while (PS, JN) have contributed with support throughout the process. All authors (IL, CSN, PS, JN, IMC) have read and approved the final manuscript.}

\section{Ethics approval and consent to participate}

Not applicable, since it is a scoping review of previously published papers.

\section{Competing interests}

The authors declare that they have no competing interests.

\section{Publisher's Note}

Springer Nature remains neutral with regard to jurisdictional claims in published maps and institutional affiliations.

Received: 23 June 2016 Accepted: 22 May 2018

Published online: 28 June 2018

\section{References}

1. Clarke S. A "Child's rights perspective": the "right" of children and young people to participate in health care research. Issues Compr Pediatr Nurs. 2015;38(3):161-80.
2. Coyne I. Accessing children as research participants: examining the role of gatekeepers. Child Care Health Dev. 2010;36(4):452-4.

3. Daly W. "Adding their flavour to the mix": involving children and young people in care in research design. Aust Soc Work. 2009;62(4):460-75.

4. Druin A. The role of children in the design of new technology. Behav Inform Technol. 2002:21(1):1-25.

5. Hill M. Children's voices on ways of having a voice: children's and young people's perspectives on methods used in research and consultation. Childhood. 2006;13(1):69-89.

6. Nygren JM, Lindberg S, Warnestal P, Svedberg P. Involving children with cancer in health promotive research: a case study describing why, what, and how. JMIR Res Protoc. 2017;6(2):e19.

7. Fargas-Malet M, McSherry D, Larkin E, Robinson C. Research with children: methodological issues and innovative techniques. J Early Child Res. 2010;8(2):175-92.

8. McLaughlin $\mathrm{H}$. Involving young service users as co-researchers: possibilities, benefits and costs. Br J Soc Work. 2006;36(8):1395-410.

9. Campbell A. For their own good: recruiting children for research. Childhood. 2008;15(1):30-49.

10. Moules T, O'Brien N. Participation in perspective: reflections from research projects. Nurs Res. 2012;19(2):17-22.

11. Powell MA, Smith AB. Children's participation rights in research. Childhood. 2009;16(1):124-42

12. Kellett M. Small shoes, big steps! Empowering children as active researchers. Am J Community Psychol. 2010;46(1-2):195-203.

13. Randall D. Revisiting Mandell's 'least adult' role and engaging with children's voices in research. Nurs Res. 2012;19(3):39-43.

14. United Nations. Conventions of the rights of the child. UNICEF. Geneva: UN; 1989

15. WHO. Engagement and participation for health equity. Cardiff: World Health Organisation; 2017.

16. Salsberg J, Parry D, Pluye P, Macridis S, Herbert CP, Macaulay AC. Successful strategies to engage research partners for translating evidence into action in community health: a critical review. J Environ Public Health. 2015;2015:191856.

17. Boaz A, Biri D, McKevitt $C$. Rethinking the relationship between science and society: has there been a shift in attitudes to patient and public involvement and public engagement in science in the United Kingdom? Health Expect. 2016;19(3):592-601.

18. Cook T, Boote J, Buckley N, Vougioukalou S, Wright M. Accessing participatory research impact and legacy: developing the evidence base for participatory approaches in health research. Educ Action Res. 2017;25(4):473-88.

19. Hart R. Children's participation: from tokenism to citizenship. In: Edited by UNICEF. Florence: UNCIEF; 1992.

20. Arnstein SR. A ladder of citizen participation. J Am Inst Plann. 1969;35(4):216-24.

21. Shier H. Pathways to participation: openings, opportunities and obligations. Child Soc. 2001;15(2):107-17.

22. Arksey H, O'Malley L. Scoping studies: towards a methodological framework. Int J Soc Res Methodol. 2005:8(1):19-32.

23. Colquhoun HL, Levac D, O'Brien KK, Straus S, Tricco AC, Perrier L, Kastner M, Moher D. Scoping reviews: time for clarity in definition, methods, and reporting. J Clin Epidemiol. 2014;67(12):1291-4.

24. United Nations. World programme of action for youth to the year 2000 and beyond. In: Edited by Assembly G, vol. A/RES/50/81: United Nations; 1995.

25. Akard TF, Gilmer MJ, Friedman DL, Given B, Hendricks-Ferguson VL, Hinds PS. From qualitative work to intervention development in pediatric oncology palliative care research. J Pediatr Oncol Nurs. 2013;30(3):153-60.

26. Beaulac J, Bouchard D, Kristjansson E. Physical activity for adolescents living in a disadvantaged neighbourhood: views of parents and adolescents on needs, barriers, facilitators, and programming. Leis. 2009:33(2):537-61.

27. Beaulieu D, Godin G. Development of an intervention programme to encourage high school students to stay in school for lunch instead of eating at nearby fast-food restaurants. Eval Program Plann. 2012;35(3):382-9.

28. Cafazzo JA, Casselman M, Hamming N, Katzman DK, Palmert MR. Design of an mHealth app for the self-management of adolescent type 1 diabetes: a pilot study. J Med Internet Res. 2012;14(3):e70.

29. Caldwell CH, Wright JC, Zimmerman MA, Walsemann KM, Williams D, Isichei PA. Enhancing adolescent health behaviors through strengthening nonresident father-son relationships: a model for intervention with AfricanAmerican families. Health Educ Res. 2004;19(6):644-56.

30. Cottrell L, Harris C, Deskins S, Bradlyn A, Coffman J. Developing culturally tailored health belief-based intervention materials to improve child and parent participation in a cardiovascular screening program. Health Promot Pract. 2010;11(3):418-27. 
31. Garofalo R, Johnson AK, Kuhns LM, Cotten C, Joseph H, Margolis A. Life skills: evaluation of a theory-driven behavioral HIV prevention intervention for young transgender women. J Urban Health. 2012;89(3):419-31.

32. Goodkind J, LaNoue M, Lee C, Freeland L, Freund R. Feasibility, acceptability, and initial findings from a community-based cultural mental health intervention for American Indian youth and their families. J Community Psychol. 2012;40(4):381-405.

33. Grant KE, Farahmand F, Meyerson DA, Dubois DL, Tolan PH, Gaylord-Harden NK, Barnett A, Horwath J, Doxie J, Tyler D, et al. Development of cities mentor project: an intervention to improve academic outcomes for low-income urban youth through instruction in effective coping supported by mentoring relationships and protective settings. J Prev Interv Community. 2014;42(3):221-42.

34. Greene K, Catona D, Elek E, Magsamen-Conrad K, Banerjee SC, Hecht ML Improving prevention curricula: lessons learned through formative research on the youth message development curriculum. J Health Commun. 2016; 21(10):1071-8.

35. Jenkins EK, Kothari A, Bungay V, Johnson JL, Oliffe JL. Strengthening population health interventions: developing the CollaboraKTion framework for community-based knowledge translation. Health Res Policy Syst. 2016;14(1):65.

36. Kong AS, Farnsworth S, Canaca JA, Harris A, Palley G, Sussman AL. An adaptive community-based participatory approach to formative assessment with high schools for obesity intervention*. J Sch Health. 2012;82(3):147-54.

37. Lutenbacher $\mathrm{M}$, Cooper W, Faccia K. Planning youth violence prevention efforts: decision-making across community sectors. J Adolesc Health. 2002; 30(5):346-54.

38. Morales-Campos DY, Parra-Medina D, Esparza LA. Picture this!: using participatory photo mapping with Hispanic girls. Fam Community Health. 2015;38(1):44-54.

39. Power TG, Bindler RC, Goetz S, Daratha KB. Obesity prevention in early adolescence: student, parent, and teacher views. J Sch Health. 2010;80(1):13-9.

40. Raghupathy S, Forth AL. The HAWK2 program: a computer-based drug prevention intervention for native American youth. Am J Drug Alcohol Abuse. 2012;38(5):461-7.

41. Resnicow K, Yaroch AL, Davis A, Wang DT, Carter S, Slaughter L, Coleman D, Baranowski T. GO GIRLS!: results from a nutrition and physical activity program for low-income, overweight African American adolescent females. Health Educ Behav. 2000;27(5):616-31.

42. Schultz JR, Butler RB, McKernan L, Boelsen R, Project HBIE. Developing theory-based risk-reduction interventions for HIV-positive young people with haemophilia. Haemophilia. 2001;7(1):64-71.

43. Sockolow P, Schug S, Zhu J, Smith TJ, Senathirajah Y, Bloom S. At-risk adolescents as experts in a new requirements elicitation procedure for the development of a smart phone psychoeducational trauma-informed care application. Inform Health Soc Care. 2017;42(1):77-96.

44. Sorensen G, Fagan P, Hunt MK, Stoddard AM, Girod K, Eisenberg M, Frazier L. Changing channels for tobacco control with youth: developing an intervention for working teens. Health Educ Res. 2004;19(3):250-60.

45. Young DR, Johnson CC, Steckler A, Gittelsohn J, Saunders RP, Saksvig BI, Ribisl KM, Lytle LA, McKenzie TL. Data to action: using formative research to develop intervention programs to increase physical activity in adolescent girls. Health Educ Behav. 2006;33(1):97-111.

46. Arvidsson S, Gilljam BM, Nygren J, Ruland CM, Nordby-Boe T, Svedberg P. Redesign and validation of Sisom, an interactive assessment and communication tool for children with cancer. JMIR Mhealth Uhealth. 2016;4(2):e76.

47. Biltoft-Jensen A, Trolle E, Christensen T, Islam N, Andersen LF, EgenfeldtNielsen S, Tetens I. WebDASC: a web-based dietary assessment software for 8-11-year-old Danish children. J Hum Nutr Diet. 2014;27(1):43-53.

48. Corder K, Schiff A, Kesten JM, van Sluijs EM. Development of a universal approach to increase physical activity among adolescents: the GoActive intervention. BMJ Open. 2015;5(8):e008610.

49. Elf M, Rystedt H, Lundin J, Krevers B. Young carers as co-designers of a webbased support system: the views of two publics. Inform Health Soc Care. 2012;37(4):203-16.

50. Goold PC, Bustard S, Ferguson E, Carlin EM, Neal K, Bowman CA. Pilot study in the development of an interactive multimedia learning environment for sexual health interventions: a focus group approach. Health Educ Res. 2006; 21(1):15-25

51. Hawkins JL, Bravo P, Gobat N, Rollnick S, Jerzembek G, Whitehead S, Chanon S, Kelson M, Adams O, Murphy S. Group motivational interviewing in schools: development of a health promotion intervention. Health Educ J. 2016;75(5):513-27.
52. Kime N, McKenna J, Webster L. Young people's participation in the development of a self-care intervention-a multi-site formative research study. Health Educ Res. 2013;28(3):552-62.

53. Lowes L, Robling MR, Bennert K, Crawley C, Hambly H, Hawthorne K, Gregory JW, Team DS. Involving lay and professional stakeholders in the development of a research intervention for the DEPICTED study. Health Expect. 2011;14(3):250-60.

54. Maynard MJ, Baker G, Rawlins E, Anderson A, Harding S. Developing obesity prevention interventions among minority ethnic children in schools and places of worship: the DEAL (DiEt and active living) study. BMC Public Health. 2009;9:480.

55. Milnes LJ, McGowan L, Campbell M, Callery P. Developing an intervention to promote young people's participation in asthma review consultations with practice nurses. J Adv Nurs. 2013;69(1):91-101.

56. Reinaerts E, de Nooijer J, de Kar A, De Vries NK. Development of a school-based intervention to promote fruit and vegetable consumption. Exploring perceptions among 4-to-12-years old children. Health Educ. 2006;106(5):345-56.

57. Ruland CM, Starren J, Vatne TM. Participatory design with children in the development of a support system for patient-centered care in pediatric oncology. J Biomed Inform. 2008;41(4):624-35.

58. Stalberg A, Sandberg A, Soderback M, Larsson T. The child's perspective as a guiding principle: young children as co-designers in the design of an interactive application meant to facilitate participation in healthcare situations. J Biomed Inform. 2016;61:149-58.

59. Warnestal P, Svedberg P, Lindberg S, Nygren JM. Effects of using child personas in the development of a digital peer support service for childhood cancer survivors. J Med Internet Res. 2017;19(5):e161.

60. Wind M, Bobelijn K, De Bourdeaudhuij I, Klepp Kl, Brug J. A qualitative exploration of determinants of fruit and vegetable intake among 10- and 11-year-old schoolchildren in the low countries. Ann Nutr Metab. 2005:49(4):228-35.

61. Arora M, Tewari A, Dhavan P, Nazar GP, Stigler MH, Juneja NS, Perry CL, Reddy KS. Discussions with adults and youth to inform the development of a communitybased tobacco control programme. Health Educ Res. 2013;28(1):58-71.

62. Mishra A, Arora M, Stigler MH, Komro KA, Lytle LA, Reddy KS, Perry CL. Indian youth speak about tobacco: results of focus group discussions with school students. Health Educ Behav. 2005;32(3):363-79.

63. Tan JL, Goh DHL, Ang RP, Huan VS. Child-centered interaction in the design of a game for social skills intervention. Comput Entertain. 2011;9(1):2.

64. Power R, Langhaug LF, Nyamurera T, Wilson D, Bassett MT, Cowan FM. Developing complex interventions for rigorous evaluation-a case study from rural Zimbabwe. Health Educ Res. 2004;19(5):570-5.

65. Wright CJ, Dietze PM, Crockett B, Lim MS. Participatory development of MIDY (Mobile Intervention for Drinking in Young people). BMC Public Health. 2016;16:184.

66. Neumark-Sztainer D, Levine MP, Paxton SJ, Smolak L, Piran N, Wertheim EH. Prevention of body dissatisfaction and disordered eating: what next? Eat Disord. 2006:14(4):265-85.

67. Reich SM, Kay JS, Lin GC. Nourishing a partnership to improve middle school lunch options: a community-based participatory research project. Fam Community Health. 2015;38(1):77-86.

68. Broström S. Children's participation in research. Int J Early Years Educ. 2012; 20(3):257-69.

69. Alderson P. Research by children. Int J Soc Res Methodol. 2001:4(2):139-53.

70. Harris J, Springett J, Croot L, Booth A, Campbell F, Thompson J, et al. Can community-based peer support promote health literacy and reduce inequalities? A realist review. Public Health Res 2015;3(3):192. https://doi.org/10.3310/phr03030

71. Christian BJ, Pearce PF, Roberson AJ, Rothwell E. It's a small, small world: data collection strategies for research with children and adolescents. J Pediatr Nurs. 2010;25(3):202-14.

72. Angell C, Alexander J, Hunt JA. 'Draw, write and tell': a literature review and methodological development on the 'draw and write' research method. J Early Child Res. 2015;13(1):17-28.

73. D'Amico M, Denov M, Khan F, Linds W, Akesson B. Research as intervention? Exploring the health and well-being of children and youth facing global adversity through participatory visual methods. Glob Public Health. 2016;11(5-6):528-45.

74. Barker J, Smith F. What's in focus? A critical discussion of photography, children and young people. Int J Soc Res Methodol. 2012;15(2):91-103.

75. Vindrola-Padros C, Martins A, Coyne I, Bryan G, Gibson F. From informed consent to dissemination: using participatory visual methods with young people with long-term conditions at different stages of research. Glob Public Health. 2016;11(5-6):636-50. 
76. Noonan RJ, Boddy LM, Fairclough SJ, Knowles ZR. Write, draw, show, and tell: a child-centred dual methodology to explore perceptions of out-ofschool physical activity. BMC Public Health. 2016;16(1):326.

77. Levac D, Colquhoun H, O'Brien KK. Scoping studies: advancing the methodology. Implement Sci. 2010;5:69.

78. Shea BJ, Hamel C, Wells GA, Bouter LM, Kristjansson E, Grimshaw J, Henry DA, Boers M. AMSTAR is a reliable and valid measurement tool to assess the methodological quality of systematic reviews. J Clin Epidemiol. 2009;62(10):1013-20

79. Daudt HM, van Mossel C, Scott SJ. Enhancing the scoping study methodology: a large, inter-professional team's experience with Arksey and O'Malley's framework. BMC Med Res Methodol. 2013;13:48.

Ready to submit your research? Choose BMC and benefit from:

- fast, convenient online submission

- thorough peer review by experienced researchers in your field

- rapid publication on acceptance

- support for research data, including large and complex data types

- gold Open Access which fosters wider collaboration and increased citations

- maximum visibility for your research: over $100 \mathrm{M}$ website views per year

At BMC, research is always in progress.

Learn more biomedcentral.com/submissions 